\title{
Comparison of Transforming Growth Factor-Beta 1 and Lovastatin on Differentiating Mesenchymal Stem Cells toward Nucleus Pulposus-like Phenotype: An In Vitro Cell Culture Study
}

\author{
Shu-Hua Yang ${ }^{1}$, Kai-Chiang Yang ${ }^{2}$, Chih-Wei Chen ${ }^{3}$, Ting-Chun Huang ${ }^{4}$, Yuan-Hui Sun ${ }^{1}$, Ming-Hsiao Hu ${ }^{1}$ \\ ${ }^{I}$ Department of Orthopedics, National Taiwan University Hospital, National Taiwan University College of Medicine, Taipei, Taiwan \\ ${ }^{2}$ Department of Dental Technology, College of Oral Medicine, Taipei Medical University, Taipei, Taiwan \\ ${ }^{3}$ Department of Orthopedics, National Taiwan University Hospital Hsin Chu Branch, Hsin Chu, Taiwan \\ ${ }^{4}$ Department of Orthopedics, National Taiwan University Hospital Chu Tung Branch, Hsin Chu, Taiwan
}

Study Design: In vitro cell culture study.

Purpose: This study aims to investigate the impact of transforming growth factor-beta1 (TGF- $\beta 1$ ) and lovastatin on differentiating human mesenchymal stem cells (MSCs) toward nucleus pulposus (NP)-like phenotype.

Overview of Literature: MSCs offer a cell source to the cell-based therapy for intervertebral disc degeneration. TGF- $\beta 1$ is used to induce MSCs to differentiate into NP-like cells; however, an undesired expression of collagen type / has been reported. Statins reportedly stimulate expression of bone morphogenetic protein-2 (BMP-2) and promote the chondrogenic phenotype to NP cells. However, the effects of statins with or without TGF- $\beta 1$ on the differentiation of MSCs into NP-like cells remain unclear.

Methods: Human MSCs were treated with TGF- $\beta 1$ alone, lovastatin alone, and simultaneous or sequential treatment with TGF- $\beta 1$ and lovastatin. After the proposed stimulation, the total RNA was extracted to assess the expression profile of NP cells-specific genes. Hematoxylin-eosin staining was used for examining the microscopic morphology. Furthermore, we detected the syntheses of S-100 protein, aggrecan, and collagen type // in the extracellular matrix using immunohistochemical staining.

Results: Simultaneous or sequential treatment of TGF- $\beta 1$ and lovastatin could further augment the BMP-2 overexpression compared with lovastatin-alone treatment. However, the mRNA expression of aggrecan and collagen type // was not compatible with the expression level of BMP-2. Immunohistochemical studies revealed compatible production of aggrecan, collagen type II, and S-100 protein in all three groups treated with lovastatin. Cells in groups treated with lovastatin were less populated than that in the group treated with TGF- $\beta 1$ alone.

Conclusions: This study demonstrates a promising role of lovastatin in inducing human MSCs into NP-like cells. However, further optimization of cell density before lovastatin treatment, treatment duration, and combination with TGF- $\beta 1$ are warranted to attain better stimulatory effects.

Keywords: Spine; Intervertebral disc degeneration; Mesenchymal stem cells; Nucleus pulposus-like cells; Lovastatin

This is the 2018 APSS-Asian Spine Journal Best Paper Award.

Received Sep 30, 2018; Revised Dec 2, 2018; Accepted Dec 30, 2018

Corresponding author: Ming-Hsiao $\mathrm{Hu}$

Department of Orthopedics, National Taiwan University College of Medicine, No.1 Jen Ai road section 1, 10051, Taipei, Taiwan R.O.C.

Tel: +886-2312-3456 (ext. 6588), Fax: +886-2322-4112, E-mail: minghsiaohu@yahoo.com.tw 


\section{Introduction}

The intervertebral disc (IVD) comprises hydrated and gelatinous nucleus pulposus (NP) core, surrounding multilaminar annulus fibrosus, and cartilaginous endplates [1]. IVD degeneration correlates with genetic, aging, and traumatic effects, causing different spinal disorders that are leading causes of chronic low back pain and high health costs [2]. The extracellular matrix (ECM) of NP comprises water, proteoglycans, and collagen that provide bearing capacity of IVD to resist the mechanical load [3]. The pathophysiological evidence demonstrates that IVD degeneration initiates from the NP, where the contents of collagen type II (Col2) and proteoglycan reduce with an abnormally increasing synthesis in collagen type I (Col1) [4]. As the NP loses the cellularity and matrix integrity and becomes fibrotic, the process becomes irreversible. The degenerated IVD cannot transmit intervertebral forces optimally, and various degenerative processes occur subsequently.

At present, no cure exists for IVD degeneration. Thus, cell-based interventions for tissue regeneration in the early stages of degeneration could theoretically delay or even reverse the degenerative process and, perhaps, restore the biological and mechanical function of IVD. One potential cell-based therapy is the transplantation of autologous IVD cells [5,6]. Clinically, the most applicable source of cells is surgically harvested IVD tissue to treat lumbar disc herniation and degenerative disc disease; however, these cells could display potentially pathological changes with a phenotype of cellular senescence [7]. Alternatively, the overexpression of catabolic cytokines and degenerative enzymes [8], as well as the declined production of matrix components, has also been reported in isolated NP cells [9]. Moreover, using autologous NP cells harvested from adjacent healthy IVDs is unfeasible; however, this approach could initiate donor IVDs degeneration [10]. Furthermore, restricted availability and suboptimal regenerative potential are major concerns to autologous differentiated NP cells [11].

Recently, uncommitted mesenchymal stem cells (MSCs) have garnered special attention in cell-based therapy for IVD degeneration. Reportedly, the use of autologous MSCs could alleviate the lack of autologous grafts, possible donor-site morbidity, allogeneic immunogenicity, and potential infection transmissions of xenogeneic cells [12]. To date, several approaches have been tested, includ- ing transplanting MSCs into IVDs [13,14], coculturing MSCs and IVD cells $[15,16]$, and differentiating MSCs toward NP-like cells by various growth factors $[14,17]$. Transforming growth factor-betal (TGF- $\beta 1$ ) could induce MSCs differentiate into NP-like cells $[17,18]$. However, we previously reported that TGF- $\beta 1$-treated MSCs displayed an enhanced synthesis of both Col2 and Col1 [16]. The overexpression of Coll signifies the fibrotic characteristics of the regenerated matrix that should be further enhanced for the NP regeneration. Statins, highly effective drugs to lower cholesterol levels, are extensively used to decrease the coronary artery disease-related morbidity [19]. Studies have reported statins to stimulate the bone morphogenetic protein-2 (BMP-2) expression and promote the expression of chondrogenic phenotype in rat chondrocytes as well as IVD cells $[20,21]$. In an in vitro study, we revealed that lovastatin upregulated genes encoding Col2, BMP-2, and transcription factor $S O X 9$ in human degenerative NP cells, whereas the Col1 expression was suppressed [22]. The subsequent animal study illustrated that the intradiscal administration of lovastatin solution enhanced BMP2 and SOX9 expressions and promoted chondrogenesis of rat caudal discs after the discography-simulated procedure $[23,24]$. Per the chondrogenic effects of BMP-2 and SOX9, lovastatin could induce the differentiation of MSCs into NP-like cells.

Hence, this study aims to examine the differences between the effects of TGF- $\beta 1$ and lovastatin on the differentiation of MSCs toward the NP-like cell phenotype. Different settings including exceptional, simultaneous, or sequential treatments with TGF- $\beta 1$ or lovastatin were tested.

\section{Materials and Methods}

We expanded commercially available human MSCs (Poietics; Lonza, Basel, Switzerland) as monolayers in tissue culture flasks in $5 \% \mathrm{CO}_{2}$ at $37^{\circ} \mathrm{C}$ in the $\mathrm{MSC}$ medium (Lonza) for later use of experiments. To mimic the native microenvironment of NP cells, all MSC cultivations were conducted in a hypoxia working station (US Autoflow NU-4950; NuAire, Plymouth, MN, USA) with a mixture of $5 \% \mathrm{O}_{2}, 5 \% \mathrm{CO}_{2}$, and $91.5 \% \mathrm{~N} 2$; this $\mathrm{O}_{2}$ concentration fulfills the requirements for a hypoxic culture that does not consume large amounts of nitrogen [25]. The basal growth medium for the following experiments was DMEM/F-12 medium containing 10\% fetal bovine se- 
rum (Gibco; Life Technologies, Grand Island, NY, USA), $100 \mathrm{nM}$ dexamethasone, $50 \mathrm{U} / \mathrm{mL}$ penicillin, $50 \mathrm{mg} / \mathrm{mL}$ streptomycin, $100 \mathrm{mg} / \mathrm{mL}$ neomycin (Sigma-Aldrich, St. Louis, MO, USA), and $25 \mathrm{mg} / \mathrm{mL}$ L-ascorbic acid (SigmaAldrich).

\section{Quantitative real-time polymerase chain reaction}

Upon reaching $80 \%$ confluence, one of the four proposed treatments was given to the MSCs. As the TGF- $\beta 1$ stimulation in the first 3 days of culture is crucial for MSCs to express a chondrogenic phenotype [26], we treated MSCs with TGF- $\beta 1$ for 72 hours in TGF- $\beta$-treated groups as follows: (1) group T: 10 ng/mL TGF- $\beta 1$ (PeproTech, Rocky Hill, NJ, USA) for 72 hours; (2) group L: $5 \mathrm{mM}$ lovastatin (Sigma-Aldrich) for 72 hours (according to our previous study [23]): (3) group T+L: simultaneous treatment with $10 \mathrm{ng} / \mathrm{mL}$ TGF- $\beta 1$ and $5 \mathrm{mM}$ lovastatin for 72 hours; and (4) group T/L: sequential treatment with $10 \mathrm{ng} / \mathrm{mL}$ TGF- $\beta 1$ for 72 hours then $5 \mathrm{mM}$ lovastatin for 72 hours.

Then, RNA was extracted using a PureLink Mini RNA kit (Invitrogen, Carlsbad, CA, USA). During the extraction process, the RNA was treated with RNase-free DNase (Qiagen, Chatsworth, CA, USA) to eliminate the influence of DNA on the reverse transcription polymerase chain reaction (PCR). The RNA content was determined with a spectrophotometer (NanoDrop 2000 UV-Vis Spectrophotometer; Thermo Fisher Scientific, Waltham, MA, USA) at $\mathrm{OD}_{260}$. The complement DNA was synthesized from the extracted RNA using the High-Capacity cDNA Reverse Transcription kit (Applied Biosystems, Foster City, CA, USA). DNA synthesized from 20 ng of RNA was used for each PCR primer. To reverse transcribe the RNA, we used random hexamers from the TaqMan RT Reagents and RT reaction mix (Applied Biosystems). For the PCR step, TaqMan Universal PCR Master Mix and Assays-on-Demand Gene Expression probes (ABI PRISM 7900HT Fast RealTime PCR System, Applied Biosystems) were used. Genes examined included those for glyceraldehydes-3-phosphate dehydrogenase (GAPDH), aggrecan (AGC), Col1, Col2, SOX9, matrix metalloproteinase (MMP)-13, and BMP2. Relative expressions were calculated by using $2^{-\Delta \Delta C T}$, where CT is the cycle threshold. Of note, the RNA expression of each target gene was normalized to that of the housekeeping gene GAPDH. Then, DCT was evaluated by subtracting CT for GAPDH from CT for each target gene. The relative expression of each target gene was evaluated using the expression of $2^{-\Delta \Delta \mathrm{CT}}$ by paired comparison of DCT values obtained from MSCs treated with $10 \mathrm{ng} / \mathrm{mL}$ TGF- $\beta 1$. Notably, expressions of target genes were evaluated 6 times in each group.

\section{Histological and immunohistochemical studies}

MSCs $\left(4 \times 10^{3}\right)$ were seeded into a well of a 48 -well glass chamber slide (Nunc Lab-Tek II, Thermo Fisher Scientific) and then cultivated with proposed treatment regimens for 2 weeks: (1) group T: 10 ng/mL TGF- $\beta 1$ (PeproTech); (2) group L: $5 \mathrm{mM}$ lovastatin (Sigma-Aldrich); (3) group $\mathrm{T}+\mathrm{L}$ : simultaneous treatment with $10 \mathrm{ng} / \mathrm{mL}$ TGF- $\beta 1$ and $5 \mathrm{mM}$ lovastatin; and (4) group T/L: sequential treatment with $10 \mathrm{ng} / \mathrm{mL}$ TGF- $\beta 1$ for 72 hours then $5 \mathrm{mM}$ lovastatin for 11 days.

After 2-week cultivation, chamber slides were fixed with $10 \%$ neutral buffered formaldehyde solution (Sigma-Aldrich) and prepared for histological inspections. The cells were stained with hematoxylin and eosin for examination of microscopic morphology.

For the immunohistochemical staining, chamber slides were immersed in a solution of methanol with $3 \% \mathrm{H}_{2} \mathrm{O}_{2}$ for 10 minutes to quench the endogenous peroxidase activity and then incubated in a serum-blocking solution for 30 minutes to block nonspecific binding. Next, the cells were labeled with streptavidin-biotin (85-8943, Histostain-Plus; Invitrogen), followed by overnight incubation of the slides with primary antibody against $A G C$, Col2, or S-100 protein (Abcam, Cambridge, MA, USA). The presence of antigens was detected by a brown color after staining with 3,30-diaminobenzidine (Invitrogen). All cells were further counterstained with hematoxylin. Finally, negative controls were sectioned and subjected to identical staining procedure; however, the first antibody was replaced by isotype immunoglobulin $\mathrm{G}$.

\section{Statistical analysis}

In this study, data obtained from each group are expressed as mean \pm standard error. Analysis of variance with posthoc Dunnett's multiple comparison tests was used to analyze the differences among groups. A difference of $p<0.05$ was considered as statistically significant. 


\section{Results}

\section{The mRNA expression of mesenchymal stem cells}

Fig. 1 shows the relative expression levels of $A G C$, Coll, Col2, SOX9, and MMP-13 genes in each group. Lovastatin-treated MSCs exhibited the highest $A G C$ expres-

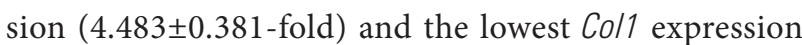

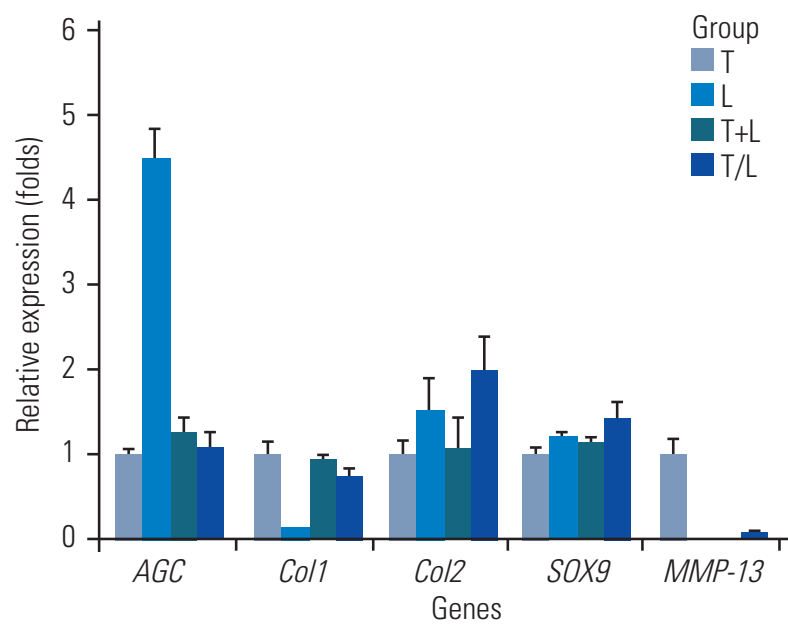

Fig. 1. Relative expressions of selected genes in each group. Group T: $10 \mathrm{ng} / \mathrm{mL}$ TGF- $\beta 1$; group L: $5 \mathrm{mM}$ lovastatin; group T+L: simultaneous treatment with $10 \mathrm{ng} / \mathrm{mL}$ TGF- $\beta 1$ and $5 \mu \mathrm{M}$ lovastatin; and group T/ $\mathrm{L}$ : sequential treatment with $10 \mathrm{ng} / \mathrm{mL}$ TGF- $\beta 1$ for 72 hours then $5 \mu$ M lovastatin for 11 days. AGC, aggrecan; Col1, collagen type l; Col2, collagen type II; MMP-13, matrix metalloproteinase-13; TGF- $\beta 1$, transforming growth factor-beta1.

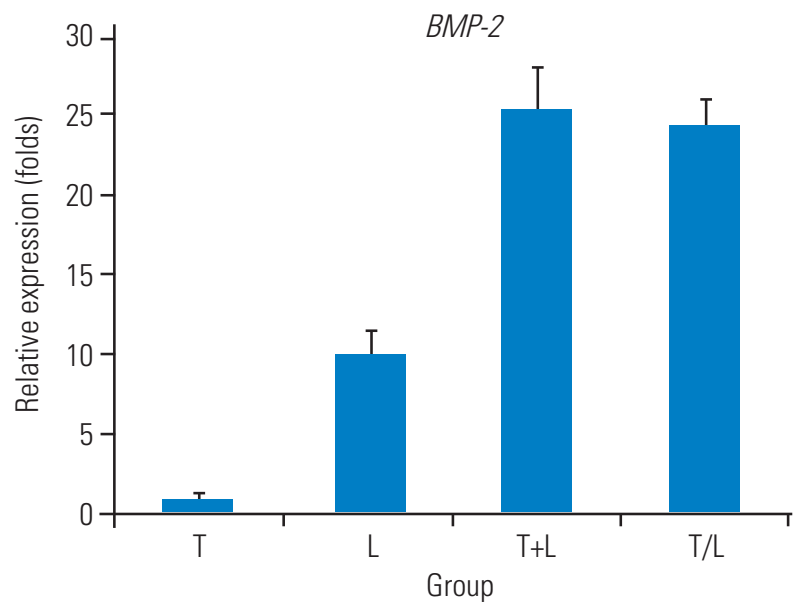

Fig. 2. Relative expressions of BMP-2. Group T: $10 \mathrm{ng} / \mathrm{mL}$ TGF- $\beta 1$; group L: $5 \mu \mathrm{M}$ lovastatin; group T+L: simultaneous treatment with 10 $\mathrm{ng} / \mathrm{mL}$ TGF- $\beta 1$ and $5 \mu \mathrm{M}$ lovastatin; and group T/L: sequential treatment with $10 \mathrm{ng} / \mathrm{mL}$ TGF- $\beta 1$ for 72 hours then $5 \mathrm{mM}$ lovastatin for 11 days. BMP-2, bone morphogenetic protein-2; TGF- $\beta 1$, transforming growth factor-beta1.
$(0.119 \pm 0.005$-fold $)$ among groups $(p<0.01)$. Otherwise, no significant difference was noted in the mRNA expression for $A G C$ and Coll among the T, T+L, and T/L groups. However, Col2 and SOX9 expressions were highest in the T/L group (1.968 \pm 0.408 -fold and $1.414 \pm 0.212$ fold, respectively), followed by the lovastatin group (1.510 \pm 0.397 -fold and 1.212 \pm 0.039 -fold, respectively). All three groups with lovastatin treatment exhibited significantly lower expression levels of MMP-13 compared with the group treated with TGF- $\beta 1$ exclusively $(p<0.01)$. Fig. 2 presents the relative expression levels of $B M P-2$ genes in each group. $B M P-2$ expression was significantly higher in all three groups with lovastatin treatment (group L, 10.214 \pm 1.169 -fold; group $\mathrm{T}+\mathrm{L}, 25.275 \pm 2.682$-fold; group $\mathrm{T} / \mathrm{L}, 24.350 \pm 1.742$-fold), and the $\mathrm{T}+\mathrm{L}$ and $\mathrm{T} / \mathrm{L}$ groups exhibited a significantly higher $B M P-2$ expression than that of the $\mathrm{L}$ group $(p<0.05)$.

\section{Hematoxylin-eosin staining}

In this study, TGF- $\beta 1$-treated MSCs displayed a cobblestone-like shape, a high nuclear-cytoplasmic ratio, and a relatively higher cell density compared with other groups (Fig. 3). In addition, the T/L group exhibited a high cell density, whereas cells in the $\mathrm{L}, \mathrm{T}+\mathrm{L}$, and $\mathrm{T} / \mathrm{L}$ groups displayed a marginally extending cytoplasm.
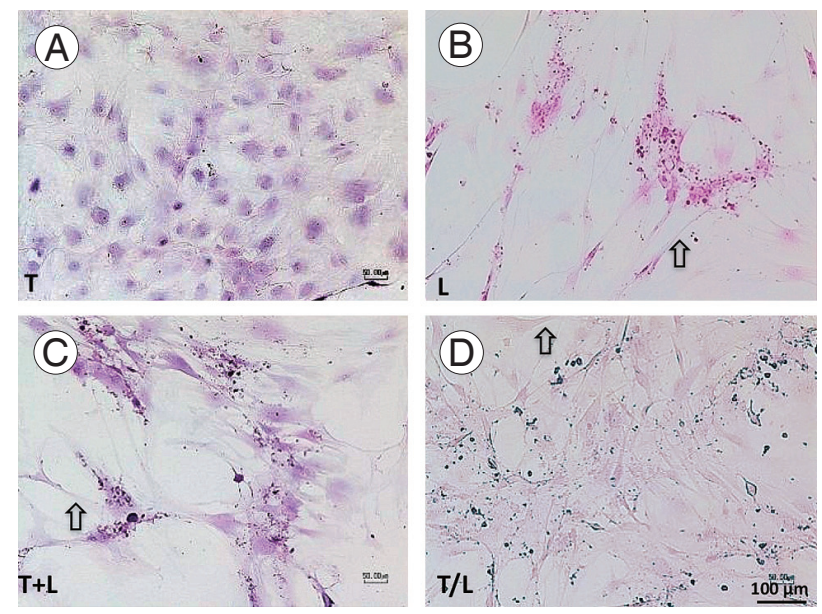

Fig. 3. (A-D) Hematoxylin-eosin staining (x100). Mesenchymal stem cells treated with TGF- $\beta 1$ (group T) display a cobblestone-like shape and a higher cell density. Cells in the $\mathrm{L}, \mathrm{T}+\mathrm{L}$, and $\mathrm{T} / \mathrm{L}$ groups display a slightly extending cytoplasm (arrow). Group T: $10 \mathrm{ng} / \mathrm{mL}$ TGF- $\beta 1$; group $\mathrm{L}: 5 \mu \mathrm{M}$ lovastatin; group T+L: simultaneous treatment with $10 \mathrm{ng} /$ $\mathrm{mL}$ TGF- $\beta 1$ and $5 \mu \mathrm{M}$ lovastatin; and group T/L: sequential treatment with $10 \mathrm{ng} / \mathrm{mL}$ TGF- $\beta 1$ for 72 hours then $5 \mu \mathrm{M}$ lovastatin for 11 days. TGF- $\beta 1$, transforming growth factor-beta1. 


\section{Immunohistochemical study}

All treated MSCs were positive to the immunohistochemical staining against $A G C$ (Fig. 4) and Col2 (Fig. 5), whereas the staining to S-100 protein was relatively weak (Fig.
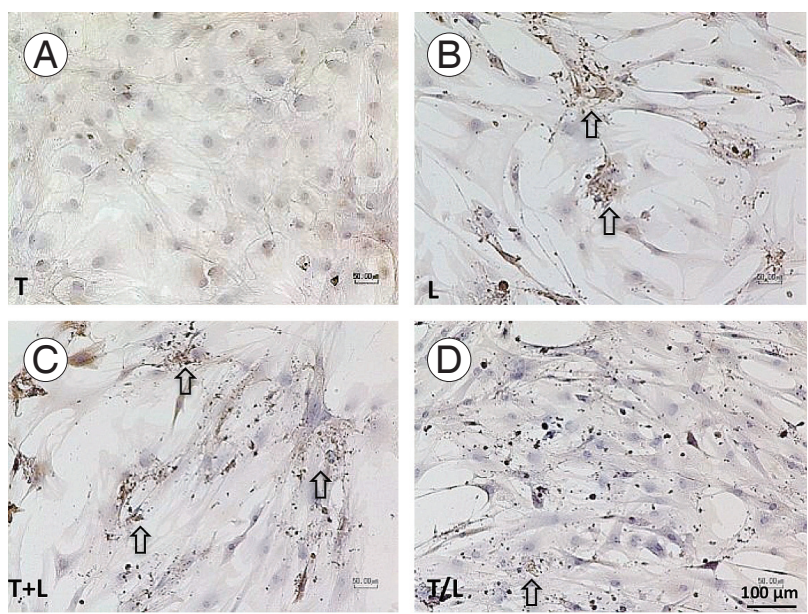

Fig. 4. (A-D) Immunochemical staining of $A G C(\times 100)$.Pronounced staining is found in lovastatin-treated groups (arrows). However, cells treated with TGF- $\beta 1$ produce $A G C$ weakly. The $T+L$ group exhibit relatively stronger $A G C$ staining than the $\mathrm{T} / \mathrm{L}$ group. Group T: $10 \mathrm{ng} / \mathrm{mL}$ TGF- $\beta 1$; group L: $5 \mu \mathrm{M}$ lovastatin; group T+L: simultaneous treatment with $10 \mathrm{ng} / \mathrm{mL}$ TGF- $\beta 1$ and $5 \mathrm{mM}$ lovastatin; and group T/L: sequential treatment with $10 \mathrm{ng} / \mathrm{mL}$ TGF- $\beta 1$ for 72 hours then $5 \mu \mathrm{M}$ lovastatin for 11 days. AGC, aggrecan; TGF- $\beta 1$, transforming growth factor-beta1.
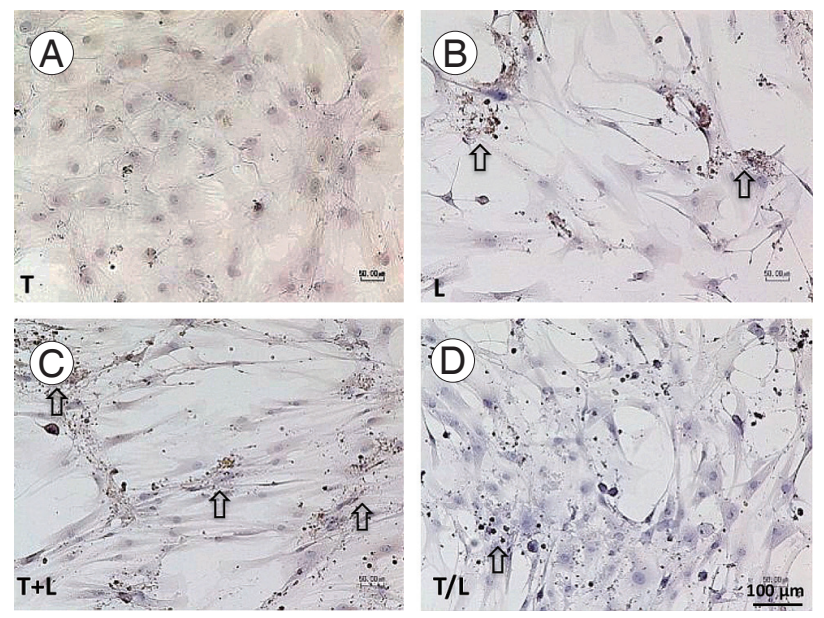

Fig. 5. (A-D) Immunochemical staining of Col2 (x100). Pronounced staining is found in lovastatin-treated groups (arrow). However, cells treated with TGF- $\beta 1$ produce Col2 weakly. The T+L group exhibit relatively stronger Col2 staining than the T/L group. Group T: $10 \mathrm{ng} / \mathrm{mL}$ TGF- $\beta 1$; group $\mathrm{L}$ : $5 \mathrm{mM}$ lovastatin; group T+L: simultaneous treatment with $10 \mathrm{ng} / \mathrm{mL}$ TGF- $\beta 1$ and 5 MM lovastatin; and group T/L: sequential treatment with $10 \mathrm{ng} / \mathrm{mL}$ TGF- $\beta 1$ for 72 hours then $5 \mu \mathrm{M}$ lovastatin for 11 days. Col2, collagen type II; TGF- $\beta 1$, transforming growth factor-beta1.
6). However, TGF- $\beta 1$-treated cells also produced $A G C$ and Col2 weakly. In addition, we found more pronounced staining of $A G C$ (Fig. 4) and Col2 (Fig. 5) in lovastatintreated groups. Furthermore, the $\mathrm{T}+\mathrm{L}$ group had relatively stronger $A G C$ and Col2 staining relative to the T/L group.

\section{Discussion}

Cell-based therapy offers a cure to regenerated IVDs, and a reliable cell source plays a vital role in this approach. Compared with unhealthy NP cells isolated from surgically excised IVD tissues, autologous MSCs serve as an alternative cell source. Although TGF- $\beta$ is used to differentiate MSCs into NP-like cells, the high expression of Col1 in these cells needs improvement [16-18]. Statins, a traditional class of drugs used to treat hypercholesterolemia, decrease the coronary artery disease-related morbidity [19]. Besides the cardioprotective effects, statins reportedly maintain NP cells, a functional phenotype, and enhance ECM synthesis in rats [21-23]. Hence, we proposed that statins could improve NP-like cells induction and be useful in IVD regeneration.

A study reported that statins could suppress the nuclear factor-kB and mitogen-activated protein kinase pathways to inhibit cell apoptosis and matrix degradation in NP cells [22]. In addition, our in vitro study further established that lovastatin upregulated Col2 and SOX9 but
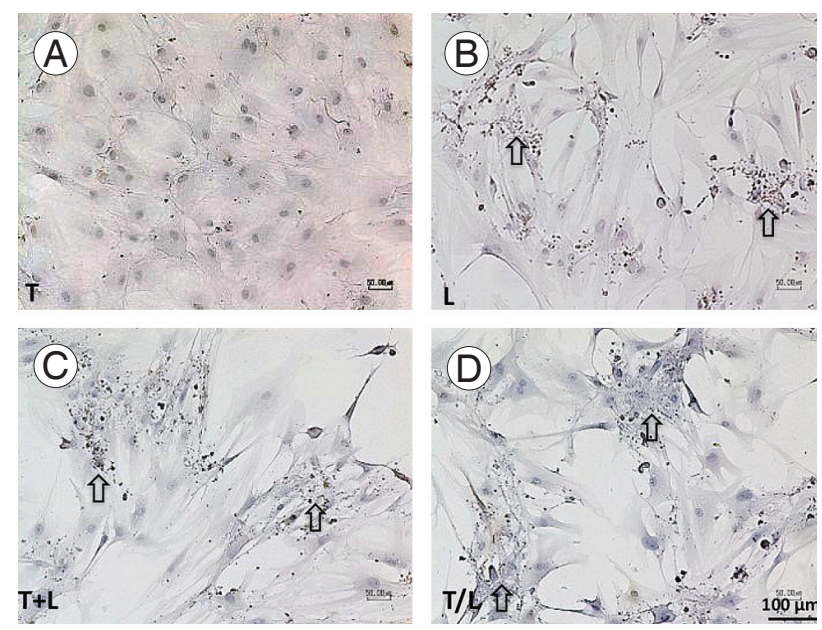

Fig. 6. (A-D) Immunohistochemical staining of S-100 protein (x100). Pronounced staining is found in lovastatin-treated groups (arrow) but not in the TGF- $\beta 1$ group. Group T: $10 \mathrm{ng} / \mathrm{mL}$ TGF- $\beta 1$; group L: $5 \mu \mathrm{M}$ lovastatin; group T+L: simultaneous treatment with $10 \mathrm{ng} / \mathrm{mL}$ TGF- $\beta 1$ and $5 \mu \mathrm{M}$ lovastatin; and group T/L: sequential treatment with $10 \mathrm{ng} /$ $\mathrm{mL}$ TGF- $\beta 1$ for 72 hours then $5 \mu \mathrm{M}$ lovastatin for 11 days. TGF- $\beta 1$, transforming growth factor-beta1. 
downregulated Coll expressions in human degenerative NP cells [23]. Reportedly, the mechanism of statins for promoting chondrogenesis of IVD cells is partly mediated by upregulated $B M P-2$ through the mevalonate pathway inhibition $[21,22,24]$. The treatment of IVD cells with $B M P-2$ enhances the proteoglycan synthesis and the expression of Col2 $[23,24,27]$. This study demonstrated that the expression of BMP-2 in human MSCs treated only with lovastatin was 10 -fold higher than that treated with TGF- $\beta 1$. In addition, simultaneous or sequential treatments of TGF- $\beta 1$ and lovastatin could further enhance the BMP-2 expression in human MSCs. Nevertheless, the expression levels of key ECM elements, such as Col2 and proteoglycans, were not compatible as $B M P$-2. These findings further corroborated our previous observations that the impact of lovastatin on NP cells or IVDs might not be entirely attributed to the $B M P$ - 2 cascade [24].

For the mRNA profiles of treated MSCs, the upregulation in $A G C$ and the suppression in Col2 were most significant in the group treated with lovastatin only. Conversely, simultaneous or sequential treatments of TGF- $\beta 1$ and lovastatin exhibited fewer effects. However, the modulation of the Col2 expression was most prominent in the group with the sequential treatment of TGF- $\beta 1$ and lovastatin; this promotional phenomenon was compatible with enhancements of the $S O X 9$ expression. In the immunohistochemical studies, productions of $A G C, \mathrm{Col}$, and S-100 protein were compatible in all three groups treated with lovastatin. The discrepancy between mRNA expressions and immunohistochemical studies could be attributed to the treatment duration or other mechanisms. Hence, further studies are warranted to optimize the effects of lovastatin on human MSCs.

In histological studies, the cells in lovastatin-treated groups were less populated than those in the group treated with only TGF- $\beta 1$. Reportedly, TGF- $\beta 1$ can induce human MSCs proliferation through the Smad3-dependent nuclear translocation of $\beta$-catenin [28]. Likewise, TGF- $\beta 1$ can also stimulate the NP cell proliferation in a dose- and timedependent manner [29]. Conversely, lovastatin reportedly decreases the proliferation of human NP cells [23]; this finding was also evident in human MSCs when treated with lovastatin. Notably, this effect might not be desirable, especially when a larger population of cells is anticipated to produce adequate ECM to restore NP tissues. At present, a few modifications to current experimental settings, including higher cell density before lovastatin treatment or shorter time of lovastatin stimulation, are under way.

\section{Conclusions}

In this study, lovastatin demonstrated a promising role in inducing human MSCs into NP-like cells. Among all groups, lovastatin-treated MSCs exhibited the highest $A G C$ expression and the lowest Coll expression. Simultaneous or sequential treatments of TGF- $\beta 1$ and lovastatin could enhance the $B M P$ - 2 overexpression compared with lovastatin-alone treatment. However, the mRNA expressions of $A G C$ and Col2 were not compatible with the $B M P$-2 expression level. In addition, immunohistochemical studies exhibited compatible productions of $A G C$, Col2, and S-100 protein in all three groups treated with lovastatin. However, cells in lovastatin-treated groups were less populated than those in the group treated with TGF- $\beta 1$ alone. Nevertheless, further optimization of treatment duration and combination is essential to achieve better results.

\section{Conflict of Interest}

No potential conflict of interest relevant to this article was reported.

\section{Acknowledgments}

Authors thank National Taiwan University Hospital (grant no., NTUH 105-S3112) for financial support.

\section{ORCID}

Shu-Hua Yang: https://orcid.org/0000-0002-9879-0164

Kai-Chiang Yang: https://orcid.org/0000-0002-0979-4463

Chih-Wei Chen: https://orcid.org/0000-0002-9309-5824

Ting-Chun Huang: https://orcid.org/0000-0002-7701-6428

Ming-Hsiao Hu: https://orcid.org/0000-0001-8920-2052

\section{References}

1. Rutges J, Creemers LB, Dhert W, et al. Variations in gene and protein expression in human nucleus pulposus in comparison with annulus fibrosus and cartilage cells: potential associations with aging and degeneration. Osteoarthritis Cartilage 2010;18:41623. 
2. Waddell G. Low back pain: a twentieth century health care enigma. Spine (Phila Pa 1976) 1996;21:2820-5.

3. Showalter BL, Beckstein JC, Martin JT, et al. Comparison of animal discs used in disc research to human lumbar disc: torsion mechanics and collagen content. Spine (Phila Pa 1976) 2012;37:E900-7.

4. Meisel HJ, Ganey T, Hutton WC, Libera J, Minkus $\mathrm{Y}$, Alasevic O. Clinical experience in cell-based therapeutics: intervention and outcome. Eur Spine J 2006;15 Suppl 3:S397-405.

5. Ganey TM, Meisel HJ. A potential role for cell-based therapeutics in the treatment of intervertebral disc herniation. Eur Spine J 2002;11 Suppl 2:S206-14.

6. Meisel HJ, Siodla V, Ganey T, Minkus Y, Hutton WC, Alasevic OJ. Clinical experience in cell-based therapeutics: disc chondrocyte transplantation A treatment for degenerated or damaged intervertebral disc. Biomol Eng 2007;24:5-21.

7. Roberts S, Evans EH, Kletsas D, Jaffray DC, Eisenstein SM. Senescence in human intervertebral discs. Eur Spine J 2006;15 Suppl 3:S312-6.

8. Le Maitre CL, Freemont AJ, Hoyland JA. Localization of degradative enzymes and their inhibitors in the degenerate human intervertebral disc. J Pathol 2004;204:47-54.

9. Sive JI, Baird P, Jeziorsk M, Watkins A, Hoyland JA, Freemont AJ. Expression of chondrocyte markers by cells of normal and degenerate intervertebral discs. Mol Pathol 2002;55:91-7.

10. Nomura T, Mochida J, Okuma M, Nishimura K, Sakabe K. Nucleus pulposus allograft retards intervertebral disc degeneration. Clin Orthop Relat Res 2001;(389):94-101.

11. Wu H, Zeng X, Yu J, et al. Comparison of nucleus pulposus stem/progenitor cells isolated from degenerated intervertebral discs with umbilical cord derived mesenchymal stem cells. Exp Cell Res 2017;361:324-32.

12. Risbud MV, Shapiro IM, Vaccaro AR, Albert TJ. Stem cell regeneration of the nucleus pulposus. Spine J 2004;4(6 Suppl):348S-353S.

13. Sakai D, Mochida J, Yamamoto Y, et al. Transplantation of mesenchymal stem cells embedded in Atelocollagen gel to the intervertebral disc: a potential therapeutic model for disc degeneration. Biomaterials 2003;24:3531-41.

14. Perez-Cruet M, Beeravolu N, McKee C, et al. Po- tential of human nucleus pulposus-like cells derived from umbilical cord to treat degenerative disc disease. Neurosurgery 2019;84:272-83.

15. Yamamoto Y, Mochida J, Sakai D, et al. Upregulation of the viability of nucleus pulposus cells by bone marrow-derived stromal cells: significance of direct cell-to-cell contact in coculture system. Spine (Phila Pa 1976) 2004;29:1508-14.

16. Yang SH, Wu CC, Shih TT, Sun YH, Lin FH. In vitro study on interaction between human nucleus pulposus cells and mesenchymal stem cells through paracrine stimulation. Spine (Phila $\mathrm{Pa} 1976$ ) 2008;33:1951-7.

17. Risbud MV, Albert TJ, Guttapalli A, et al. Differentiation of mesenchymal stem cells towards a nucleus pulposus-like phenotype in vitro: implications for cell-based transplantation therapy. Spine (Phila $\mathrm{Pa}$ 1976) 2004;29:2627-32.

18. Steck E, Bertram H, Abel R, Chen B, Winter A, Richter W. Induction of intervertebral disc-like cells from adult mesenchymal stem cells. Stem Cells 2005;23:403-11.

19. Maron DJ, Fazio S, Linton MF. Current perspectives on statins. Circulation 2000;101:207-13.

20. Hatano H, Maruo A, Bolander ME, Sarkar G. Statin stimulates bone morphogenetic protein-2, aggrecan, and type 2 collagen gene expression and proteoglycan synthesis in rat chondrocytes. J Orthop Sci 2003;8:842-8.

21. Zhang H, Lin CY. Simvastatin stimulates chondrogenic phenotype of intervertebral disc cells partially through BMP-2 pathway. Spine (Phila Pa 1976) 2008;33:E525-31.

22. Tu J, Li W, Zhang Y, et al. Simvastatin inhibits IL-1 $\beta$ induced apoptosis and extracellular matrix degradation by suppressing the NF-kB and MAPK pathways in nucleus pulposus cells. Inflammation 2017;40:72534.

23. Hu MH, Hung LW, Yang SH, Sun YH, Shih TT, Lin $\mathrm{FH}$. Lovastatin promotes redifferentiation of human nucleus pulposus cells during expansion in monolayer culture. Artif Organs 2011;35:411-6.

24. Hu MH, Yang KC, Chen YJ, Sun YH, Yang SH. Lovastatin prevents discography-associated degeneration and maintains the functional morphology of intervertebral discs. Spine J 2014;14:2459-66.

25. Erwin WM, Las Heras F, Islam D, Fehlings MG, In- 
man $\mathrm{RD}$. The regenerative capacity of the notochordal cell: tissue constructs generated in vitro under hypoxic conditions. J Neurosurg Spine 2009;10:51321.

26. Mehlhorn AT, Schmal H, Kaiser S, et al. Mesenchymal stem cells maintain TGF-beta-mediated chondrogenic phenotype in alginate bead culture. Tissue Eng 2006;12:1393-403.

27. Yoon ST, Kim KS, Li J, et al. The effect of bone morphogenetic protein-2 on rat intervertebral disc cells in vitro. Spine (Phila Pa 1976) 2003;28:1773-80.
28. Jian H, Shen X, Liu I, Semenov M, He X, Wang XF. Smad3-dependent nuclear translocation of betacatenin is required for TGF-beta1-induced proliferation of bone marrow-derived adult human mesenchymal stem cells. Genes Dev 2006;20:666-74.

29. Zhang R, Ruan D, Zhang C. Effects of TGF-betal and IGF-1 on proliferation of human nucleus pulposus cells in medium with different serum concentrations. J Orthop Surg Res 2006;1:9. 